02

\title{
Спектральное исследование протонирования фотохромных хроменов в полимерных матрицах
}

\author{
(C) О.В. Венидиктова ${ }^{1}$, О.И. Кобелева ${ }^{1}$, А.М. Горелик ${ }^{1}$, В.А. Барачевский ${ }^{1,2, \text { ฯ }}$ \\ ${ }^{1}$ Центр фотохимии ФНИЦ „Кристаллография и фотоника“ РАН, \\ 119421 Москва, Россия \\ ${ }^{2}$ Межведомственный центр аналитических исследований при Президиуме РАН, \\ 117997 Москва, Россия \\ I e-mail: barachevsky@mail.ru \\ Поступила в редакцию 17.05.2021 г. \\ В окончательной редакции 09.06.2021 г. \\ Принята к публикации 09.06.2021 г.
}

Впервые получены протонные комплексы фотоиндуцированной окрашенной формы хроменов в полимерных связующих. Показано, что УФ облучение фотохромных хроменов приводит к спектральным изменениям, обусловленным структурой соединений и природой полимерного связующего.

Ключевые слова: фотохромизм, хромен, нафтопиран, полимерная матрица, спектроскопия.

DOI: $10.21883 /$ OS.2021.10.51490.2298-21

\section{Введение}

Среди известных фотохромных органических соединений фотохромные хромены отличаются высокой устойчивостью к необратимым фотопревращениям, поэтому они были использованы для создания фотохромных офтальмологических линз [1-3]. Функционализированные фотохромные хромены оказались приемлемыми для разработки оптических хемосенсоров [4-6], фотопереключателей, фотоуправляемых молекулярных электронных устройств и др. [7].

Фотохромные превращения этих соединений основаны на обратимой фотодиссоциации $\mathrm{C}-\mathrm{O}-$ связи в пирановом цикле бесцветного циклического соединения А и последующей цис-транс-изомеризации с образованием окрашенной формы В (схема 1). Обратная реакция осуществляется спонтанно и ускоряется при нагревании или под действием видимого света.

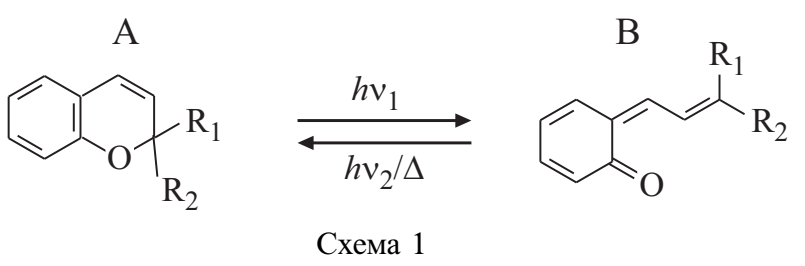

В отличие от фотохромных спиросоединений (спиропиранов и спирооксазинов), для которых известно, что под действием УФ света в присутствии кислот они образуют протонные комплексы [8], для хроменов такая информация практически отсутствует. Основные исследования были связаны с изучением влияния внутримолекулярных водородных связей на термическую стабильность мероцианиновой формы функционализированных хроменов [9-15].

Настоящая работа является продолжением исследований по изучению фотоиндуцированного протонирования мероцианиновой формы хроменов в растворах [16].

\section{Экспериментальная часть}

В качестве фотохромных хроменов использовались соединения I и II. Соединение I было синтезировано по известной методике [17]. Хромен II получали из 3,36-ди(4- метоксифенил)-8-гидрокси[3Н]нафто[2,1-b]пирана и 1-(2-фторфенил)-1'-(4-метоксифенил) -2-пропин-1-ола в растворе безводного толуола при нагревании до $60^{\circ} \mathrm{C}$ в присутствии толуолсульфокислоты в качестве катализатора.<smiles>COc1ccc(C2(c3ccc(OC)cc3)C=Cc3c(ccc4ccccc34)O2)cc1</smiles><smiles>COc1ccc(C2(OC)C=Cc3c(ccc4c3C=CC3OC(c5ccc(OC)cc5)(c5ccccc5F)C=CC43)O2)cc1</smiles>

Исследования проводились в полиметилметакрилатных (ПММА) и поливинилбутиральных (ПВБ) пленках. Для получения полимерных пленок фотохромное 


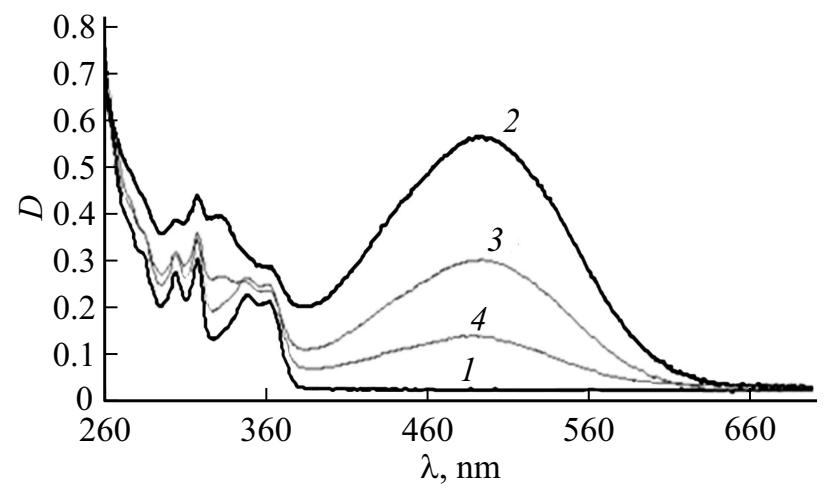

Pис. 1. Спектры поглощения соединения I в ПВБ пленке до (1), после УФ облучения (2) и в процессе темновой релаксации в исходное состояние $(3,4)$.

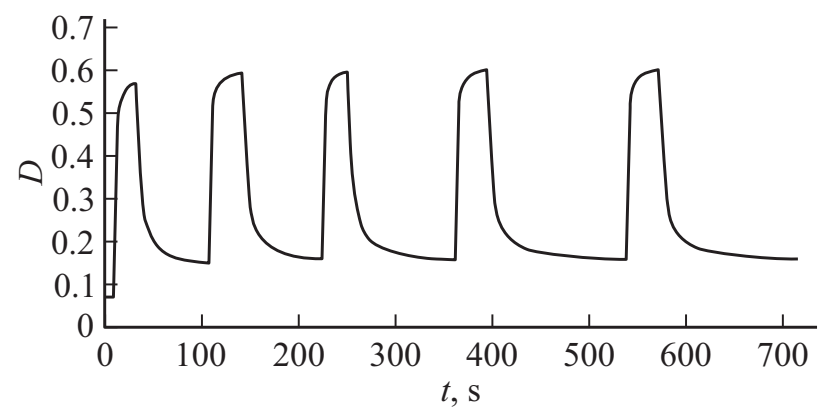

Рис. 2. Кинетика фотоокрашивания под действием УФ излучения и темнового спонтанного обесцвечивания соединения I в ПВБ пленке при регистрации на длине волны $495 \mathrm{~nm}$.

соединение в количестве $0.5 \mathrm{mg}$ растворяли в $1 \mathrm{ml}$ метоксипропанола. В полученный раствор добавляли $50 \mathrm{mg}$ полимера (5 mas.\%) Приготовленную композицию наносили на кварцевое стекло методом полива (крупной каплей). Для приготовления образца с протонированным комплексом в полимерную композицию с фотохромным соединением добавляли $0.02 \mu 1$ раствора кислоты $\mathrm{HClO}_{4}$ в метоксипропаноле $\left(C=10^{-3} \mathrm{M}\right.$ и $\left.C=10^{-2} \mathrm{M}\right)$, а затем полимерный раствор с протонированным комплексом наносили на кварцевое стекло.

Спектрофотометрические измерения (фотостационарные спектры) исследуемого соединения в полимерных слоях проводили с использованием спектрофотометра „CARY 50 bio“.

Облучение осуществляли фильтрованным светом лампы LC-4 Hamamatsu. Для фотоокрашивания использовался стеклянный светофильтр УФС-1, пропускающий УФ излучение.

\section{Результаты и их обсуждение}

На рис. 1 приведены фотоиндуцированные изменения спектра поглощения хромена I в ПВБ пленке в отсутствие кислоты. Первоначально бесцветная пленка при облучении УФ светом окрашивается с появлением по- лосы поглощения с максимумом при $490 \mathrm{~nm}$ (таблица). Она обладает фотохромными свойствами (рис. 2).

При добавлении в состав полимерного раствора соединения I хлорной кислоты $\left(C=10^{-3} \mathrm{M}\right)$, как и в отсутствие кислоты, пленка остается бесцветной до облучения и окрашивается после УФ облучения (рис. 3). Различие заключается в появлении второй длинноволновой полосы поглощения с максимумом при $635 \mathrm{~nm}$, которая батохромно смещена на $153 \mathrm{~nm}$ относительно первой полосы поглощения при $482 \mathrm{~nm}$ (таблица). Эта полоса поглощения, наблюдаемая в присутствии кислоты и в растворе [16], связывается с протонированием фенолятного кислорода фотоиндуцированной окрашенной формы В [16]. Появление коротковолновой полосы поглощения обусловлено молекулами фотоиндуцированной окрашенной формы В хромена, которые не участвуют в протонировании.

Подобно пленке, не содержащей кислоты, протонированные комплексы проявляют фотохромизм, поскольку наблюдаются обратимые фотоиндуцированные изменения ее оптической плотности (рис. 4). При этом скорость термической релаксации фотоиндуцированной формы в исходное состояние существенно снижается. В отсутствие кислоты скорость темнового обесцвечивания этой формы характеризуется сложной кинетикой, описываемой константами

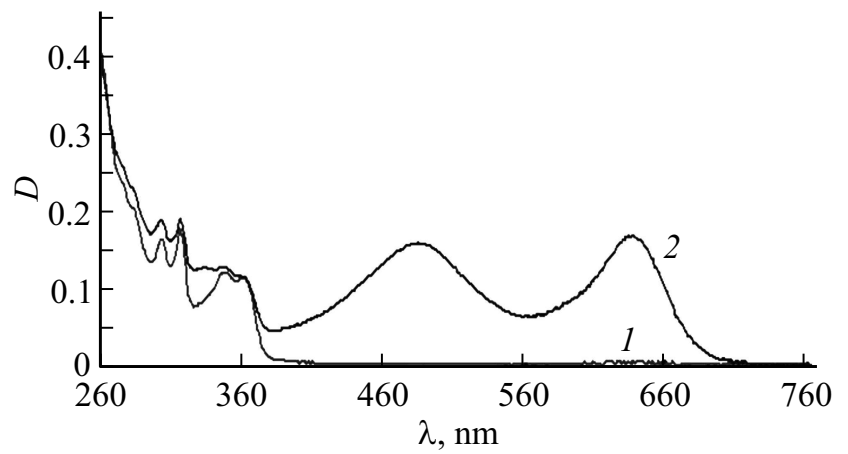

Рис. 3. Спектры поглощения соединения I в ПВБ пленке в присутствии хлорной кислоты $\left(C=10^{-3} \mathrm{M}\right)$ до $(1)$ и после УФ облучения (2).

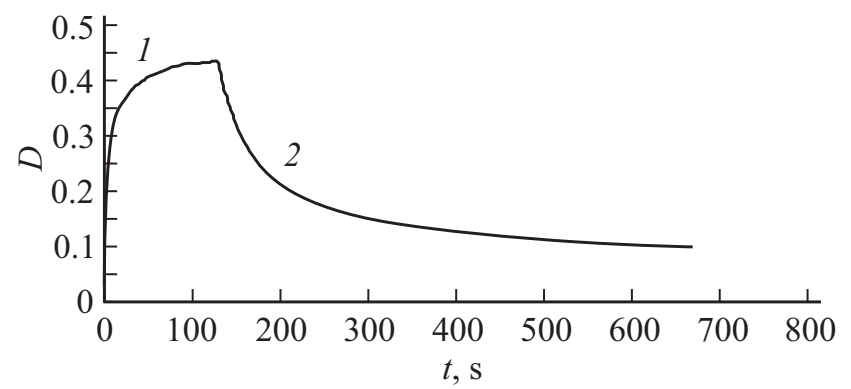

Рис. 4. Кинетика фотоокрашивания (1) и темнового обесцвечивания (2) протонированного комплекса соединения I в ПВБ пленке в присутствии хлорной кислоты $\left(C=10^{-3} \mathrm{M}\right)$ при регистрации на длине волны $635 \mathrm{~nm}$. 
Спектрально-кинетические характеристики фотохромных хроменов и протонных комплексов в полимерных пленках

\begin{tabular}{|c|c|c|c|c|}
\hline Соединение & $\mathrm{CHClO}_{4}, \mathrm{M}$ & $\lambda_{\mathrm{A}}^{\text {макс }}, \mathrm{nm}$ & $\lambda_{\mathrm{B}}^{\text {мaкс }}, \mathrm{nm}$ & $\Delta D^{\text {कот }}$ \\
\hline \multirow[t]{5}{*}{ I } & - & $355,345,313,300$ & 490 & 0.56 \\
\hline & \multirow[t]{2}{*}{$10^{-3}$} & \multirow[t]{2}{*}{$355,345,313,300$} & 482 & 0.16 \\
\hline & & & 635 & 0.16 \\
\hline & \multirow[t]{2}{*}{$10^{-2}$} & \multirow[t]{2}{*}{$355,350,313,300,494,635$} & 484 & 0.10 \\
\hline & & & 635 & 0.10 \\
\hline \multirow[t]{5}{*}{ II } & - & $395,375,326,311$ & 505 & 0.15 \\
\hline & \multirow[t]{2}{*}{$10^{-3}$} & \multirow[t]{2}{*}{$395,375,326,311$} & 500 & 0.08 \\
\hline & & & 700 & 0.06 \\
\hline & \multirow[t]{2}{*}{$10^{-2}$} & \multirow[t]{2}{*}{$395,375,326,311,500,700$} & 500 & 0.06 \\
\hline & & & 700 & 0.17 \\
\hline
\end{tabular}

Примечание. $\mathrm{CHClO}_{4}-$ концентрация хлорной кислоты в полимерном слое; $\lambda_{\mathrm{A}}^{\text {макс }}$ и $\lambda_{\mathrm{B}}^{\text {макс }}$ - длины волн максимумов полос поглощения исходной и длинноволновых полос поглощения фотоиндуцированной форм фотохромных хроменов соответственно; $\Delta D^{\text {фот }}-$ фотоиндуцированное значение оптической плотности в максимумах полос поглощения фотоиндуцированной формы В хроменов.

$k_{1}=0.190 \mathrm{c}^{-1}$ и $k_{2}=0.038 \mathrm{c}^{-1}$, а в присутствии кислоты $\left(C=10^{-3} \mathrm{M}\right)-k_{1}=0.03 \mathrm{c}^{-1}$ и $k_{2}=0.005 \mathrm{c}^{-1}$. Скорости фотоиндуцированного образования окрашенной открытой и протонированной форм оказались сравнимыми.

Увеличение концентрации кислоты на порядок приводит к появлению окраски пленки до УФ облучения, что сопровождается появлением в исходном спектре поглощения двух полос поглощения с максимумами при 484 и $635 \mathrm{~nm}$, совпадающими с максимумами полос фотоиндуцированного поглощения при меньшей концентрации кислоты (ср. спектры на рис. 5 и 3). Как и в растворах [16], вещества, образующиеся до УФ облучения, как и фотоиндуцированные протонированные комплексы, не обесцвечиваются под действием видимого света, но чрезвычайно медленно релаксируют в исходную бесцветную форму А. Возможно, это обусловлено образованием ассоциатов протонированных окрашенных форм.

Подобные результаты получены и для бис-хромена II (рис. 6 и 7, таблица). При этом возникающая вторая полоса поглощения батохромно смещена на $200 \mathrm{~nm}$ относительно фотоиндуцированной коротковолновой полосы поглощения. Это смещение на $47 \mathrm{~nm}$ больше, чем для монохромена I, что, возможно, обусловлено различной планарностью протонированных форм монои бис-хромена.

ПММА пленки хромена II проявляют фотохромные превращения, подобные наблюдаемым в растворе (рис. 8, кривые 1,2).

В отличие от пленок на основе ПВБ связующего в твердых ПММА слоях присутствие кислоты в виде появления длинноволновых полос поглощения не проявляется (рис. 8, кривые 3,4). Протонированные комплексы обнаруживаются только в гелеобразных слоях (рис. 8, кривые 5, 6).

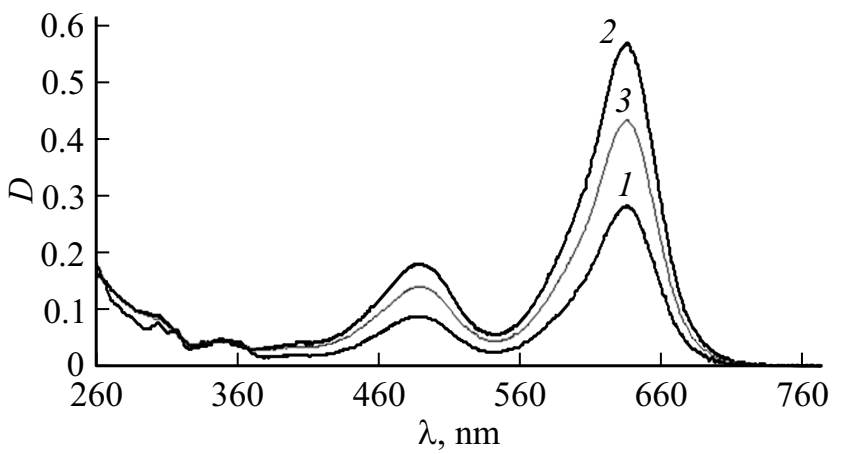

Рис. 5. Спектры поглощения соединения I в ПВБ пленке в присутствии хлорной кислоты $\left(C=10^{-2} \mathrm{M}\right)$ до $(1)$, после УФ облучения (2) и в процессе последующей спонтанной релаксации (3).

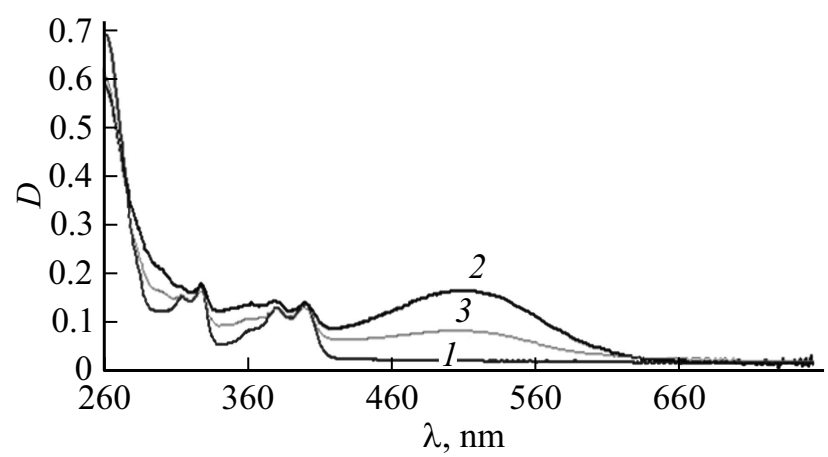

Pис. 6. Спектры поглощения соединения II в ПВБ пленке в присутствии хлорной кислоты $\left(C=10^{-3} \mathrm{M}\right)$ до $(1)$, после УФ облучения (2) и в процессе последующей спонтанной релаксации (3).

Наблюдаемое различие в образовании протонированных комплексов в ПВБ и ПММА пленках объясняется различием в жесткости и, как следствие, в свободном 


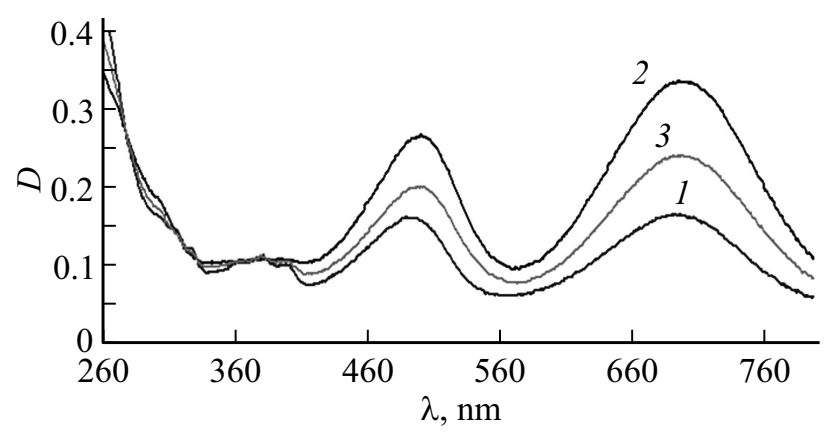

Pис. 7. Спектры поглощения соединения II в ПВБ пленке в присутствии хлорной кислоты $\left(C=10^{-2} \mathrm{M}\right)$ до $(1)$, после УФ облучения (2) и в процессе спонтанной релаксации (3).

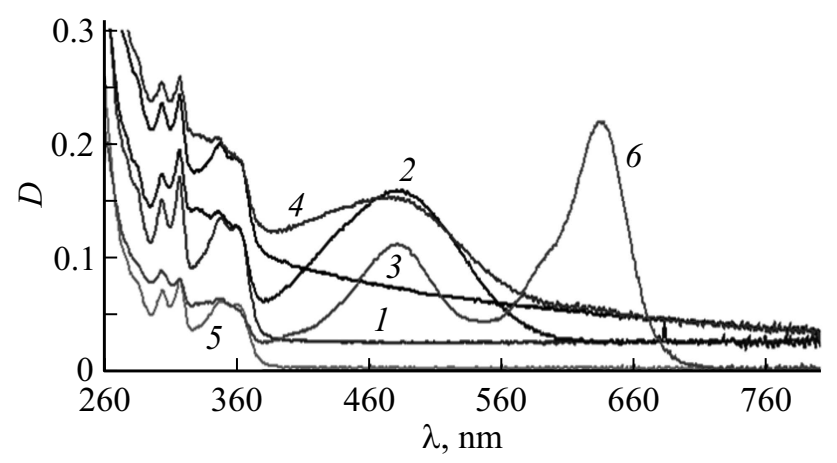

Рис. 8. Спектры поглощения соединения II в ПММА пленке в отсутствие хлорной кислоты $(1,2)$, в присутствии кислоты в твердом $(3,4)$ и гелеобразном $(5,6)$ слоях до $(1,3,5)$ и после УФ облучения $(2,4,6)$.

молекулярном объеме этих полимерных пленок. В пользу этого свидетельствует образование протонированных комплексов в гелеобразных слоях ПММА.

\section{Выводы}

Впервые продемонстрировано образование протонных комплексов фотоиндуцированной окрашенной формы хроменов в полимерных связующих. Показано, что УФ облучение фотохромных хроменов приводит к спектральным изменениям, обусловленным структурой соединений и природой полимерного связующего.

В случае ПВБ связующего протонирование происходит подобно процессу, наблюдаемому в растворах, что доказывается появлением второй полосы поглощения в длинноволновой области спектра (с максимумами при 630 и $700 \mathrm{~nm}$ для хроменов I и II соответственно). Следует заметить, что при избытке кислоты в слое уже изначально образуется протонированный комплекс без воздействия УФ света.

Полиметилметакрилатный слой в отличие от ПВБ пленки препятствует протонированию хромена. Эффект наблюдается только в гелеобразной композиции.

\section{Финансирование работы}

Работа выполнена при поддержке Министерства науки и высшего образования в рамках выполнения работ по Государственному заданию ФНИЦ „Кристаллография и фотоника“ РАН.

\section{Конфликт интересов}

Авторы заявляют, что у них нет конфликта интересов.

\section{Список литературы}

[1] Towns A.D. // Applied Photochemistry. Eds.: Bergamini G., Silvi S. Springer International Publishing AG Switzerland. 2016. Ch. 5. V. 92 . P. 227-280.

[2] Zhang J., Tian H. // Photochromic Materials. Eds.: Tian H., Zhang J. Wiley-VCH. 2016. Ch. 10. P. 393-408.

[3] Gemert V.B. // Organic Photochromic and Thermochromic Compounds. / Ed. by Crano J., Gugliemetti R. NY.: Plenum Press, 1999. V. 1. P. 111-141.

[4] Paramonov S.V., Lokshin V., Fedorova O.A. // J. Photochem. Phobiol. C. 2011. V. 12. N 3. P. 209. doi 10.1016/j.jphotochemrev.2011.09.001

[5] Barachevsky V.A. // Rev. J. Chem. 2013. V. 3. P. 52. doi 10.1134/S2079978012040012

[6] Sahoo P.R., Prakash K., Kumar S. // Coord. Chem. Rev. 2018. V. 357. P. 18. doi 10.1016/j.ccr.2017.11.010

[7] Mukhopadhyay A., Moorthy J.N. // J. Photochem. Photobiol. C. 2016. V. 29. P. 73. doi 10.1016/j.jphotochemrev.2016.11.002

[8] Halbritter T., Kaiser C., Wachtveitl J., Heckel A. // J. Org. Chem. 2017. V. 82. P. 8040. doi 10.1021/acs.joc.7b01268

[9] Martins C.I., Coelho P.J., Carvalho L.M., Oliveira-Campos A.M.F. // Tetrahed. Lett. 2002. V. 43. P. 2203. doi 10.1016/S0040-4039(02)00234-4

[10] Domingues M.R.M., Domingues P., Oliveira M.M., Carvalho L.H.M., Oliveira-Campos A.F., Correia A.J.F. // Rapid Commun. Mass Spectrom. 2004. V. 18. P. 2969. doi $10.1002 / \mathrm{rcm} .1713$

[11] Han S., Chen Y. // J. Mater. Chem. 2011. V. 21. P. 12402. doi $10.1039 / \mathrm{c} 1 \mathrm{jm} 11267 \mathrm{~h}$

[12] Frigoli M., Maurel F., Berthet J., Delbaere S., Marrot J., Oliveira M.M. // Org. Lett. 2012. V. 14. P. 4150. doi 10.1021/o1301812e

[13] Paramonov S., Fedorov Y., Lokshin V., Tulyakova E., Vermeersch G., Delbaere S., Fedorova O. // Org. Biomol. Chem. 2012. V. 10. P. 671. doi 10.1039/c1ob06501g

[14] Frigoli M., Marrot J., Gentili P.L., Jacquemin D., Vagnini M., Pannacci D., Ortica F. // ChemPhysChem. 2015. V. 16. P. 2447. doi 10.1002/cphc.201500251

[15] Berdnikova D.V., Paululat T., Jonusauskas G., Peregudova S.M., Fedorova O.A. // Org. Lett. 2017. V. 19. P. 5633. doi 10.1021/acs.orglett.7b02798

[16] Gorelik A.M., Venidiktova O.V., Kobeleva O.I., Valova T.M., Barachevsky V.A. // Dyes and Pigments. 2021. V. 184. Art. 10883. doi 10.1016/j.dyepig.2020.108833

[17] Zhao W., Gerreira E.M. // Org. Lett. 2003. V. 5. N 22. P. 4153. doi $10.1021 / \mathrm{o} 1035599 x$ 